\title{
Insertion of cellulase gene in yeast expression vector (pYY1 and pWYH257 Plasmid) as a candidate for cellulosic ethanol-producing strain
}

\author{
ARIEF MUAMMAR ${ }^{1, \bullet}$, INDAH OKTAVIANA ${ }^{1}$, JOSEPH CHOHANSANDHIKA ${ }^{1}$, \\ NIKEN SATUTI NUR HANDAYANI ${ }^{2}$ \\ ${ }^{1}$ Laboratory of Microbiology, Faculty of Biology, Universitas Gadjah Mada. Jl. Teknika Selatan, Senolowo, Sinduadi, Mlati, Sleman 55281, Yogyakarta, \\ Indonesia. Tel./fax.+62-274-580839, `email: arief.muammar@ugm.ac.id \\ ${ }^{2}$ Laboratory of Genetics and Breeding, Faculty of Biology, Universitas Gadjah Mada. Jl. Teknika Selatan, Senolowo, Sinduadi, Mlati, Sleman 55281, \\ Yogyakarta, Indonesia. Tel./fax. +62-274-580839.
}

Manuscript received: 19 November 2020. Revision accepted: 21 April 2021.

\begin{abstract}
Muammar A, Oktaviana I, Chohansandhika J, Handayani NSN. 2021. Insertion of cellulase gene in yeast expression vector ( $P Y Y 1$ and pWYH257 Plasmid) as a candidate for cellulosic ethanol-producing strain. Biodiversitas 22: 2715-2721. Production of ethanol from cellulose-based materials often faces obstacles because it requires extensive pretreatment and large amounts of cellulase enzymes. Another method that is more efficient is by inserting cellulase genes from cellulolytic microorganisms such as Aspergillus niger which possess cellulase enzymes encoded by $c b h A$ gene. This gene is inserted into the host which will then be used to produce candidate strains able to produce cellulosic ethanol. This study aimed to insert $c b h A$ gene into vector with a strong promoter to form the candidate. Total RNA was isolated from Aspergillus niger and converted into cDNA. The $c b h A$ gene is amplified from cDNA, then used as insert and inserted into yeast expression vector pYY1 and pWYH257. Vector and inserts were cut using restriction enzymes. Ligation products were transformed into competent cells of Escherichia coli DH10B, the transformation results were confirmed by Colony PCR. Recombinant plasmids were transformed into Saccharomyces cerevisiae INVSc1. The results obtained from the study are that $c b h A$ gene amplification has been successfully carried out by producing DNA bands with the size of 1514 bp as expected for the target gene. The gene was successfully inserted into pYY1 and pWYH257 vector and the recombinant pYY1 plasmid was successfully transformed into Saccharomyces cerevisiae INVSc1.
\end{abstract}

Keywords: $A D H 1$ promotor, Aspergillus niger, cbhA gene, TEF1 promotor, yeast expression vector

\section{INTRODUCTION}

Fossil fuels are the main resource to fulfill the increasing of energy demand (Akorede et al. 2010). In Indonesia, $75 \%$ of the total energy consumption comes from fossil fuels and the consumption rate of this nonrenewable energy increases by $7 \%$ every year (Hasan et al. 2012). The gap between the demand and the availability of resources is becoming larger because the availability of fossil fuel in nature is decreasing and new fields are not yet well developed yet. On the other hand, the use of fossil fuels is also the main cause of global warming, so it is necessary to find alternative renewable and environmentally friendly energy sources, one of which is bioethanol (Kholiq 2015). The main raw material for bioethanol production is biomass-derived from starch, which will be hydrolyzed by amylase enzyme to produce glucose. Besides starch, there is another alternative raw material, i.e., biomass from the cellulosic group. The cellulosic materials are considered more promising for bioethanol production, because these materials are abundant, cheap, renewable, and environmentally friendly when used as raw materials for producing alternative energy (Yamada et al. 2011).

Cellulose is the most abundant biopolymer composed of repeated D-glucose residues connected by $\beta$-1,4-glycosidic bonds ( $\mathrm{Li}$ et al. 2014), so it needs to be hydrolyzed first to produce glucose as a material for fermentation with bioethanol as the end product. The process of ethanol production using cellulosic biomass can be carried out by utilizing cellulolytic microbes because these microbes have cellulase enzymes. These cellulolytic microbes found in several ecosystems such as in the forests, ruminant digestive animal tract, until in bio-slurry in husbandry area (Yang et al. 2014, Muammar et al. 2021). There are three types of cellulase enzymes needed to hydrolyze cellulose into glucose monomers, they are endoglucanase (endocellulase), exoglucanase (cellobiohydrolase) and $\beta$ glucosidase (cellobiose). One example of cellulase enzymes is the enzyme encoded by the cbhA (cellobiohydrolase A) gene owned by Aspergillus niger. This cellobiohydrolase enzyme will break down cellulose (van Munster et al. 2014). Microbes such as Saccharomyces cerevisiae is often used in the production of bioethanol from biomass that contains sugar, because this microbe has the ability to degrade sucrose into simple sugars like glucose, and can act as a fermenter in the bioethanol production process (Busic et al. 2018).

On industrial scale, the cost of hydrolysis process using cellulosic biomass with addition of enzymes is expensive because hydrolysis of cellulose materials requires extensive pretreatment and large amount of cellulase enzymes for 
efficient hydrolysis process (Viikari et al. 2012). Therefore, another method is needed, so the enzymes that used in the hydrolysis process can be produced by the microorganisms themselves. Molecular cloning can be used to create microbial strains able to hydrolyze cellulose. These microbe strains can be generated by inserting cellulase gene from cellulolytic microorganisms into the host cell, which then able to produce bioethanol by fermentation. This will provide benefits to the bioethanol industry. This study aimed to insert the $c b h A$ cellulase gene from Aspergillus niger into the yeast expression vector (pYY1 plasmid with $A D H 1$ promoter and pWYH257 plasmid with TEF1 promoter) as candidate for cellulosic ethanolproducing strain. pYY1 and pWYH257 plasmids were derived from the expression vector pQB169. The expression vector pQB169 is derivative of the plasmid YEplac181 which has LEU2 as selectable marker and has ADH promoter as strong constitutive promoter, with ILS1 as transcription terminator (Wakasugi et al. 1988). A strong promoter like $A D H 1$ and $T E F 1$, indicates that this promoter has a high level of transcription which causes a high level of enzyme expression as well (Xiong et al. 2018). This research is expected to create recombinant microbial strain as part of the solution for the fuels problem in the future.

\section{MATERIALS AND METHODS}

\section{Study area}

This research was conducted at the Laboratory of Microbiology and Joint Research Facility (FALITMA) in Faculty of Biology Universitas Gadjah Mada, Yogyakarta, Indonesia; Laboratory of Microbiology at Biotechnology Study Center (PAU) and Integrated Research and Testing Laboratory (LPPT) in Universitas Gadjah Mada.

\section{RNA preparation}

The RNA sample used in this research is obtained from previous research by Muammar et al. (2020). The RNA used was isolated from Aspergillus niger, from Microbiology Laboratory, Faculty of Biology, Universitas Gadjah Mada culture collection. The RNA was then stored at $-80^{\circ} \mathrm{C}$.

\section{Synthesis of cDNA and cellulase gene amplification}

iScript cDNA Synthesis Kit by Bio-Rad was used to convert RNA templates into cDNA and My Taq HS Red Mastermix Kit by Bioline was used to amplify cellulase genes from cDNA. The condition for cDNA synthesis is presented in Table 1.

The cDNA was then used as a DNA template to amplify the cellulase gene. The amplification process used a specific primer for the $\operatorname{cbh} A$ gene that has been added with the PstI restriction enzyme sequence at the forward primer end and SpeI on the reverse primer end. Primer of cbhA was designed manually using Benchling. This software also used to check the cutting site on plasmids which will be a consideration for selecting restriction enzymes (Muammar et al. 2020). The program for $c b h A$ gene amplification can be seen in Table 2. The results of cellulase gene amplification were electrophoresed and then visualized using UV transilluminator to see the amplified genes.

Table 1. Condition for synthesis of cDNA

\begin{tabular}{lccc}
\hline \multicolumn{1}{c}{ Segment } & $\begin{array}{c}\text { Number of } \\
\text { cycles }\end{array}$ & $\begin{array}{c}\text { Temperature } \\
\left({ }^{\mathbf{O}} \mathbf{C}\right)\end{array}$ & Duration \\
\hline Priming & 1 & 25 & $5 \mathrm{~min}$ \\
Reverse Transcription & 1 & 46 & $20 \mathrm{~min}$ \\
RT Inactivation & 1 & 95 & $1 \mathrm{~min}$ \\
Optional Step & 1 & 4 & $1 \mathrm{~h}$-stop \\
\hline
\end{tabular}

Note: The program for synthesis of cDNA consist of four segments (priming, reverse transcription, rt inactivation, and optional step)

Table 2. PCR condition for $c b h A$ gene amplification

\begin{tabular}{lccc}
\hline \multicolumn{1}{c}{ Segment } & $\begin{array}{c}\text { Number of } \\
\text { cycles }\end{array}$ & $\begin{array}{c}\text { Temperature } \\
\left({ }^{\circ} \mathbf{C}\right)\end{array}$ & Duration \\
\hline Pre-denaturation & 1 & 95 & $1 \mathrm{~min}$ \\
Denaturation & & 95 & $15 \mathrm{sec}$ \\
Annealing & $35 \mathrm{X}$ & 56 & $15 \mathrm{sec}$ \\
Extension & & 72 & $1 \mathrm{~min} 40 \mathrm{sec}$ \\
Post Extension & 1 & 72 & $5 \mathrm{~min}$ \\
\hline
\end{tabular}

Note: The PCR condition for $c b h A$ gene amplification consists of five segments (pre-denaturation, denaturation, annealing, extension, and post extension)

\section{Insertion of the cbhA gene into the yeast expression vector (pYY1 and pWYH257) and transformation to Escherichia coli DH10B}

The amplified $c b h A$ gene (insert) and the vectors (pYY1 and pWYH257 obtained from WCC Laboratory, National Central University, Taiwan) were digested by using PstI-HF and SpeI-HF restriction enzymes. The digested products were incubated at $37^{\circ} \mathrm{C}$ for 12 hours, then $0.5 \mu \mathrm{L}$ of Calf Intestinal Phosphatase (CIP) was added to the pYY1 and pWYH257 plasmid, and then the incubation was extended for one hour. Furthermore, the insert and the vector were ligated by using T4 DNA Ligase enzyme, then the mixture was incubated at $16{ }^{\circ} \mathrm{C}$ for 12 hours. The ligation product was transformed into Escherichia coli DH10B cells by electroporation method at an electrical voltage of $1.8 \mathrm{KV}$, a capacitance of $25 \mu \mathrm{F}$, and a resistance of $100 \Omega$ for $2-3$ seconds. The transformed $E$. coli was mixed with $1 \mathrm{~mL}$ of SOC medium and agitated for 1 hour at $37^{\circ} \mathrm{C} 200 \mathrm{rpm}$. The pellets were collected using a centrifuge at room temperature and at a speed of 10000 rpm for 1 minute. The pellets were inoculated with spread plate method on Luria Bertani (LB) agar medium with Ampicillin $\left(100 \mathrm{mg} \mathrm{L}^{-1}\right)$, and then incubated at $37^{\circ} \mathrm{C}$ for 24 hours.

\section{Colony PCR}

The transformed colonies were confirmed by the Colony PCR method. Colonies grown on Luria Bertani agar medium with Ampicillin $\left(100 \mathrm{mg} \mathrm{L}^{-1}\right)$ were taken a bit using a sterile pipette tip and mixed with My Taq HS Red Mastermix reaction component by Bioline. The specific primers and programs used in Colony PCR are the same as the primers and programs used to amplify the previous 
cbhA gene. Colony PCR products were electrophoresed and then visualized using UV-Transilluminator. Colonies with positive results were subcultured on Luria Bertani liquid medium and Terrific Broth (TB) medium with Ampicillin (100 $\mathrm{mg} \mathrm{L}^{-1}$ ), the cultures were then purified.

\section{Transformation into Saccharomyces cerevisiae INVSc1}

The purified transformed Escherichia coli with positive results were then transformed into Saccharomyces cerevisiae INVSc1 by chemical method using heat shock at $45^{\circ} \mathrm{C}$ for 5 minutes. The transformed results were incubated in ice for 3 minutes. After incubation, the pellets of the transformed result were taken from the supernatant and then the pellets were resuspended with $80 \mu \mathrm{L} 1 \mathrm{X}$ TE. The results of the transformation were inoculated on Synthetic Drop-Out without Leucine agar medium using the spread plate method and incubated at $30^{\circ} \mathrm{C}$ for 3 days.

\section{Data analysis}

All amplified genes/fragments visualized by electrophoresis and quantified by spectrophotometer. Bacteria and yeast transformant spread in LB Ampicillin medium and Synthetic Drop-Out without Leucine agar medium respectively. All sequence data is analyzed by comparing the data obtained to the related literature and National Center for Biotechnology Information (NCBI) database.

\section{RESULTS AND DISCUSSION}

\section{Amplification of $\operatorname{cbh} A$ gene via PCR}

In this present study, total RNA from Aspergillus niger previously grown in CMC medium and produced a positive result in cellulase assays, this method also called Congo Red/Iodine assays (Gohel et al. 2014), needed to be extracted as a template for $c b h A$ amplification. Total RNA extraction was performed to avoid three introns which are to be eliminated by spliceosome during RNA splicing (Jo and Choi 2015). We performed cell lysis using liquid nitrogen followed by grinding with mortar (Motkova and
Vytrasova 2011). We used liquid nitrogen to prevent RNA destruction because it only freezes fungi cell walls. In addition, low temperature of liquid nitrogen hinders RNase enzyme activity so RNA degradation can be prevented (Fabre et al. 2014). After fungal cell lysis, we performed a total RNA isolation using YeaStar RNA Kit from Zymo Research. Total RNA was stored in $-80^{\circ} \mathrm{C}$ freezer for further use.

To amplify the cellulase gene present in eukaryotic microorganisms such as Aspergillus niger, total RNA isolation is carried out first. Total RNA was chosen as the initial sample for the RT-PCR process rather than mRNA, because less purification steps were needed so that there would be more sample quantities that could be used as a template. mRNA is more sensitive to the purification stage. After being isolated, the RNA must be converted into cDNA, and this cDNA will be used as a template for amplification of the cellulase gene.

Two-step RT-PCR was used to amplify $c b h A$ gene. Complementary DNA of total RNA was synthesized through reverse transcription, and subsequently, the cDNA was used as a template for $c b h A$ amplification through PCR. Amplicon visualization (Figure 1) on agarose gel electrophoresis resulted in about 1500 bp DNA bands.

In Figure 1, DNA bands were produced from the cbhA gene, the DNA band on the left side was used to insert the cbhA gene into yeast expression vector pYY1 and the DNA band on the right side was used to insert the cbhA gene into yeast expression vector pWYH257. The size of the DNA band is different from the marker size, because we combined 3 wells into 1 large well to magnify its visualization.

According to the NCBI database, Aspergillus niger cbhA (KT886077.1) gene size is 1514 bp. The results showed that DNA amplified in the present study is suitable to target gene $\operatorname{cbh} A$ because it has approximately similar size to the target gene. Therefore, this DNA band was then purified and used as an insert for molecular cloning. Purification was done to avoid DNA fragments other than cbhA.

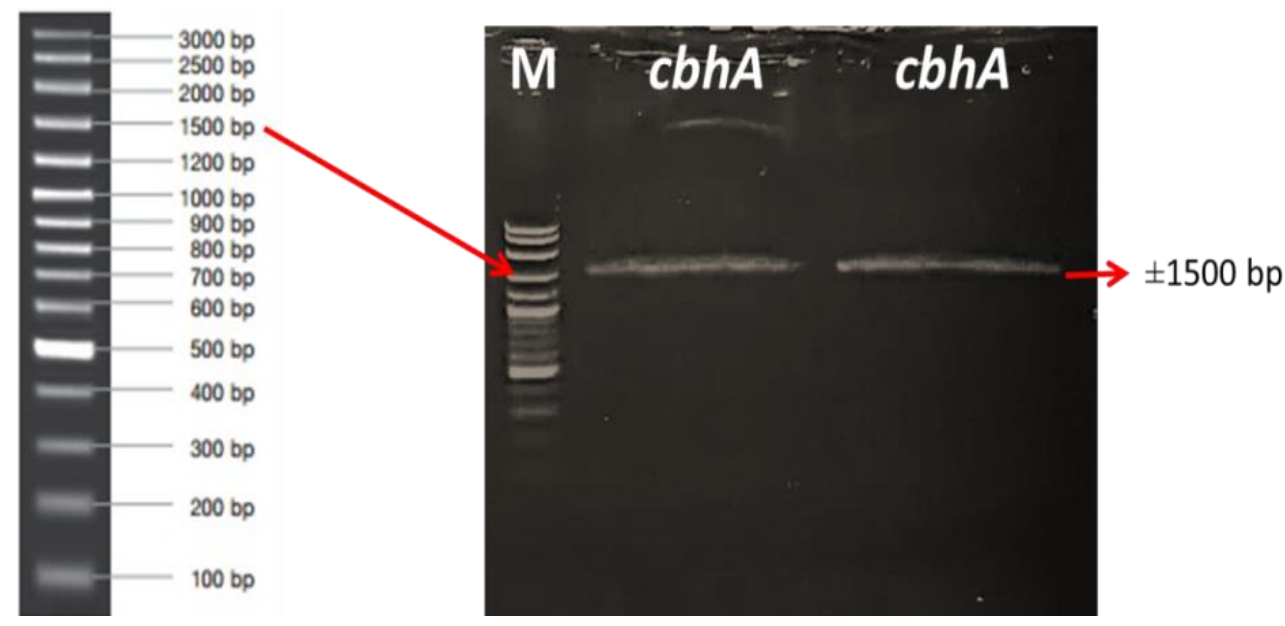


Figure 1. Amplicon of $c b h A$ on $0.8 \%$ agarose gel ( $\mathrm{M}=$ Marker 100 bp plus "Vivantis")

\section{Insertion of $\boldsymbol{c b h} A$ gene into yeast expression vectors and transformation to Escherichia coli DH10B}

Vector and insert were digested by PstI-HF and SpeI$H F$ restriction enzymes. Restriction enzyme site candidates were picked appropriately (Taheri et al. 2012), where the chosen restriction sites were confirmed not to be located in the insert sequence so restriction enzymes would not cut in the middle of the sequence. It was also confirmed that the restriction enzyme site used was in the Multiple Cloning Site (MCS) of the vector, and the PstI-HF and SpeI-HF restriction enzyme sites were not in any other part of the vector sequence.

$A D H 1$ promoter in pYY1 plasmid is a promoter derived from Saccharomyces cerevisiae for alcohol dehydrogenase gene which has active fermentative isozymes, needed in the process of reducing acetaldehyde to ethanol (Raj et al. 2014). Translation elongation factor EF-1 alpha (TEF1) is a gene encoding EF-1 $\alpha$ which functions to promote the binding of aminoacyl-tRNA to GTP-dependent ribosomes and participate in proof-reading of codon-anticodon pairs (Song et al. 1989). ADHI and TEFI promoters as strong promoters having a high transcription level which causes their enzyme expression level to be high (Xiong et al. 2018). The vectors pYY1 and pWYH2577 have AmpR which indicates that the vector has resistance to antibiotic, in this case, Ampicillin, so that the plasmid which has this AmpR marker can grow on a medium containing Ampicillin. The size of plasmid pYY1 with $A D H 1$ promoter is 5926 bp. At the Multiple Cloning Site (MCS) in plasmid pYY1, there are unique restriction enzyme recognition sites, including the PstI, EagI, SpeI, NdeI, and XhoI enzymes. The size of plasmid pWYH257 with TEF1 promoter is $6256 \mathrm{bp}$, and its construction is almost similar to pYY1 with change in $A D H 1$ promoter to TEF1 promoter. These plasmid constructions can be seen in Figure 2.

In this research, PstI and SpeI restriction enzymes were used which can produce "sticky ends" or "overhang" cuts, so that the vector and insert can be combined during the ligation process. Furthermore, Calf Intestinal Phosphatase was added to prevent both ends of the vector from selfligation. Digestion results were purified and visualized with UV Transilluminator.
In the ligation stage, the process was carried out by adding the T4 DNA ligase enzyme. This enzyme catalyzes the formation of covalent phosphodiester bonds, which permanently hold the nucleotides together. The ligation product was transformed into Escherichia coli DH10B cells using electroporation method so that cell membrane pores can be slightly opened and the recombinant plasmids were able to enter the cell. Escherichia coli DH10B was used as a competent cell because it has high efficiency for transformation, and the ability to stably retrieve and store large plasmids. These bacteria also have incomplete defense system for exogenous DNA (Wang et al. 2020).

Positive transformants were indicated by colonies that could grow on LB agar medium with Ampicillin (100 mg $\left.\mathrm{L}^{-1}\right)$. Ampicillin is an antibiotic used to selectively eliminate bacteria that have not been transformed with plasmids without Ampicillin resistant gene. From the results (Figure 3.A and 3.C), many transformants grew on the positive control of pYY1 and pWYH257. This indicates that the transformation carried out has fairly high efficiency because the plasmid transformed into a competent cell was an intact plasmid. On the other hand, results of the ligation product pYY1-cbhA transformation showed that 35 colonies grew on LB agar medium with Ampicillin (Figure 3.B), and ligation product pWYH257-cbhA transformation exhibited 9 colonies growth (Figure 3.D). The number of transformant cells containing ligation products was less than those containing intact plasmid, because only a few number of recombinant plasmids that are ligated to become recombinant plasmids, or the recombinant plasmid transformation process is unstable so that it becomes incomplete and non-functional. Transformant cells that grow to form colonies at this stage only indicate if the transformant cell has a part of the ligation product, namely plasmid pYY1 and pWYH257, so the success of inserting the $\operatorname{cbh} A$ gene needs to be further examined by knowing the presence of the insert. One assay that we used in this research to distinguish between ligated and non-ligated recombinant plasmid is using colony PCR which the steps was mentioned in the methods.

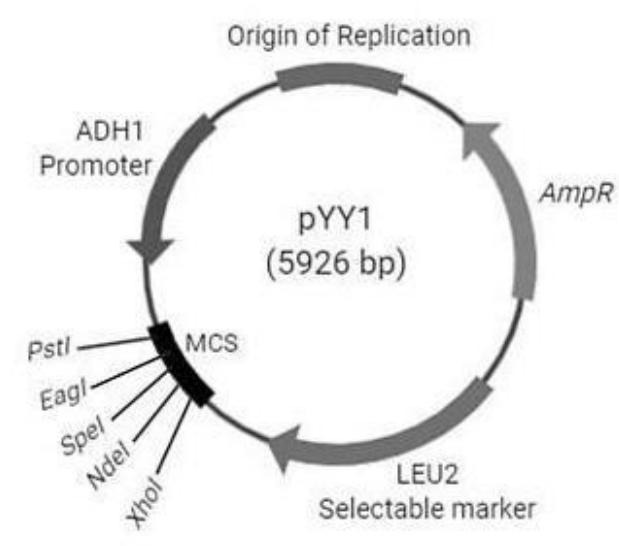

A

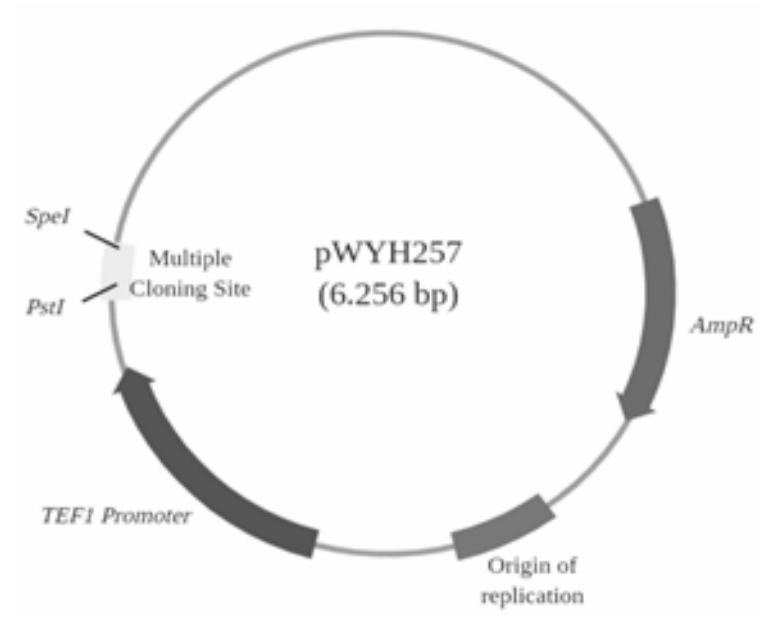

B 
Figure 2. Yeast expression vector: A. pYY1, and B. pWYH257
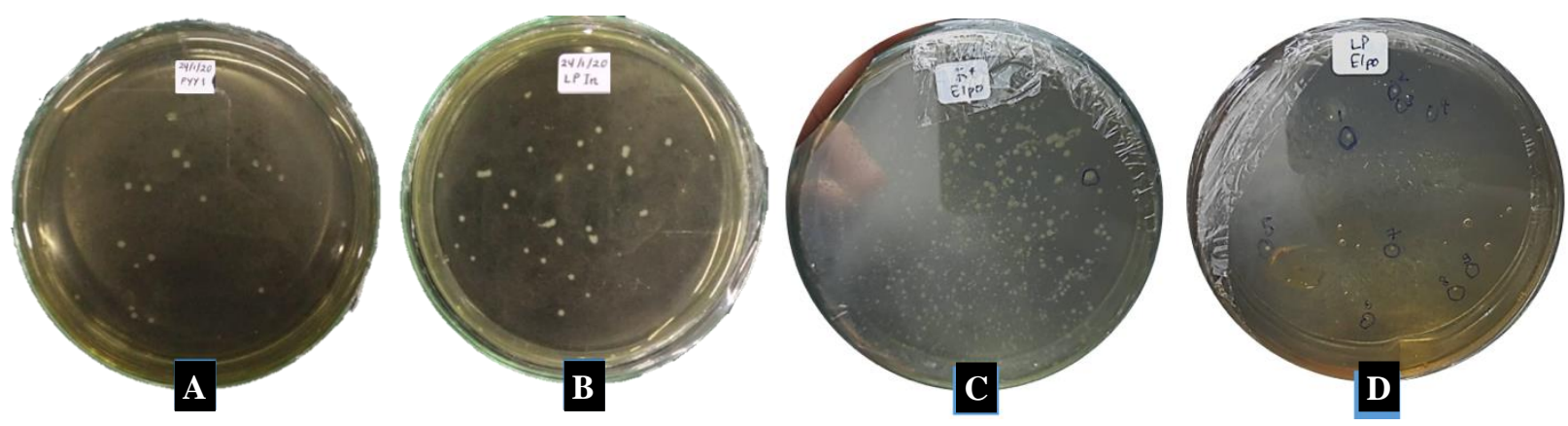

Figure 3. Transformants growth on LB agar with Ampicillin: A. Positive control pYY1, B. Ligation product pYY1-cbhA, C. Positive control pWYH257, D. Ligation product pWYH257-cbhA.

\section{Colony PCR}

Colony PCR is a method for determining the presence or absence of DNA inserts in the constructed plasmid in the colony (Jamal et al. 2017). This method involves a PCR process that uses a specific primer to amplify the $\operatorname{cbh} A$ gene that has been added with the PstI restriction enzyme sequence at the forward primer end and SpeI on the reverse primer end, and was inserted into the pYY1 and pWYH257 vector. Furthermore, the presence of PCR amplicons and the size of the PCR amplicons were seen through visualization of the electrophoresis results along with DNA size markers on agarose gel. Transformants grown on LB Agar with Ampicillin (100 mg $\left.\mathrm{L}^{-1}\right)$ were sampled aseptically to be used as a template for the amplification of the $\operatorname{cbhA}$ gene. DH10B capsule and cell membrane were lysed during the pre-denaturation process, and the DNA was isolated for PCR amplification (Figure 4).

It can be seen from Figure 4 that the positive control ( $\operatorname{cbh} A$ gene) shows the presence of DNA bands size of \pm 1500 bp. The negative control (pYY1 and pWYH257 vector) showed no DNA bands because this plasmid did not contain DNA insert ( $c b h A$ gene) and it is valid to be used. The transformants of pYY1-cbhA LP 2, LP 3, LP 4, LP 5, LP 6, LP 7, LP 8, LP 9, and LP 10 (in lane 4-12 sequentially) showed positive results which were marked by the presence of DNA bands size of $\pm 1500 \mathrm{bp}$, LP 1 in lane 3 showed negative result which was marked by the lack of presence DNA bands size of $\pm 1500 \mathrm{bp}$. The transformants of pWYH257-cbhA 1, 3, 5, 7, and 9 also showed positive results by appearance of \pm 1514 bp DNA bands, the same size as $c b h A$ gene in the NCBI database. The appearance of DNA bands other than $\pm 1,514 \mathrm{bp}$ size is probably due to random attachment of primers that are not specific to the $c b h A$ gene, or it is also possible to happen by high similarity sequence between primer and sequence in this sample, but it is not $c b h A$ gene site. The transformant without the DNA band size of \pm 1.514 bp indicates that the plasmid in the transformant contained no $c b h A$ gene insert.

\section{Transformation to Saccharomyces cerevisiae INVSc1}

The recombinant plasmids obtained in the previous stage were then transformed into Saccharomyces cerevisiae INVSc1 cells which had been prepared previously with $\mathrm{LiAc} / \mathrm{TE}$ solution. The results of the transformation were then inoculated on Synthetic Drop-Out without Leucine agar medium. This medium is commonly used for plasmid selection in yeast based on the mutant auxotrophs strain, where these strains will not be able to grow without a specific component in the medium (such as amino acid, purine, or pyrimidine). The Synthetic Drop-Out without Leucine agar medium contains all kinds of amino acids except the leucine amino acid, so the one that can grow on this medium is the transformed plasmid that has a gene with LEU selectable marker.

In Figure 5, the positive control shows the growth of 57 colonies, the results of LP2 transformation show the growth of 68 colonies, the results of LP3 transformation show the growth of 24 colonies, while the results of LP7 transformation show the growth of 54 colonies. Positive control, LP2, LP3, LP7 were successfully transformed into Saccharomyces cerevisiae INVSc1 and they can grow on Synthetic Drop-Out without Leucine agar medium because they contain plasmid with LEU2 selectable marker, so the ligated product can express and produce leucine amino acid by itself. 

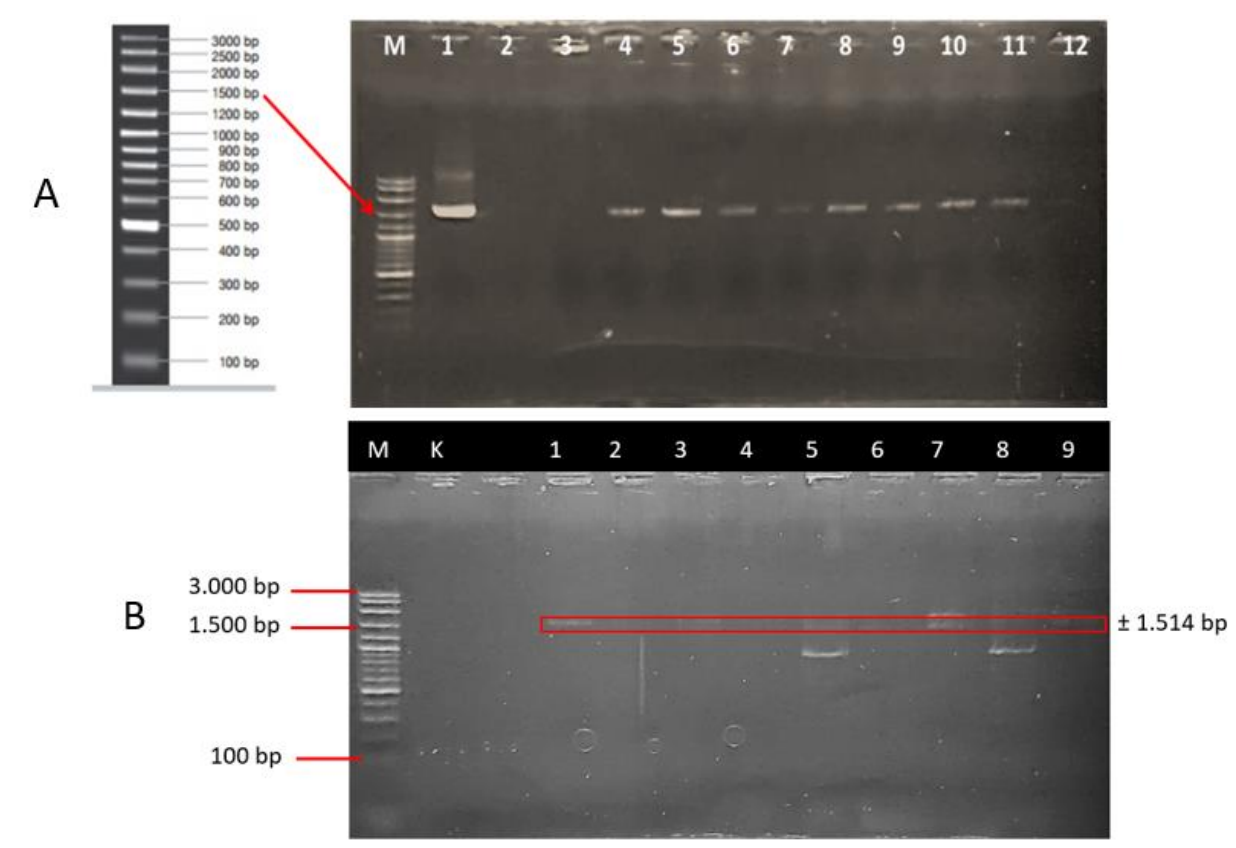

Figure 4. Visualization of Colony PCR amplification (A: $\mathrm{M}=$ Marker 100 bp plus "Vivantis", lane $1=c b h A$ as positive control, lane 2 $=$ pYY1 transformant as negative control, lane 3-12 = transformants of pYY1-cbhA LP1-LP10; and B: M = Marker, K = pWYH257 transformant as negative control, lane 1-9 = transformant of pWYH257-cbhA 1-9)
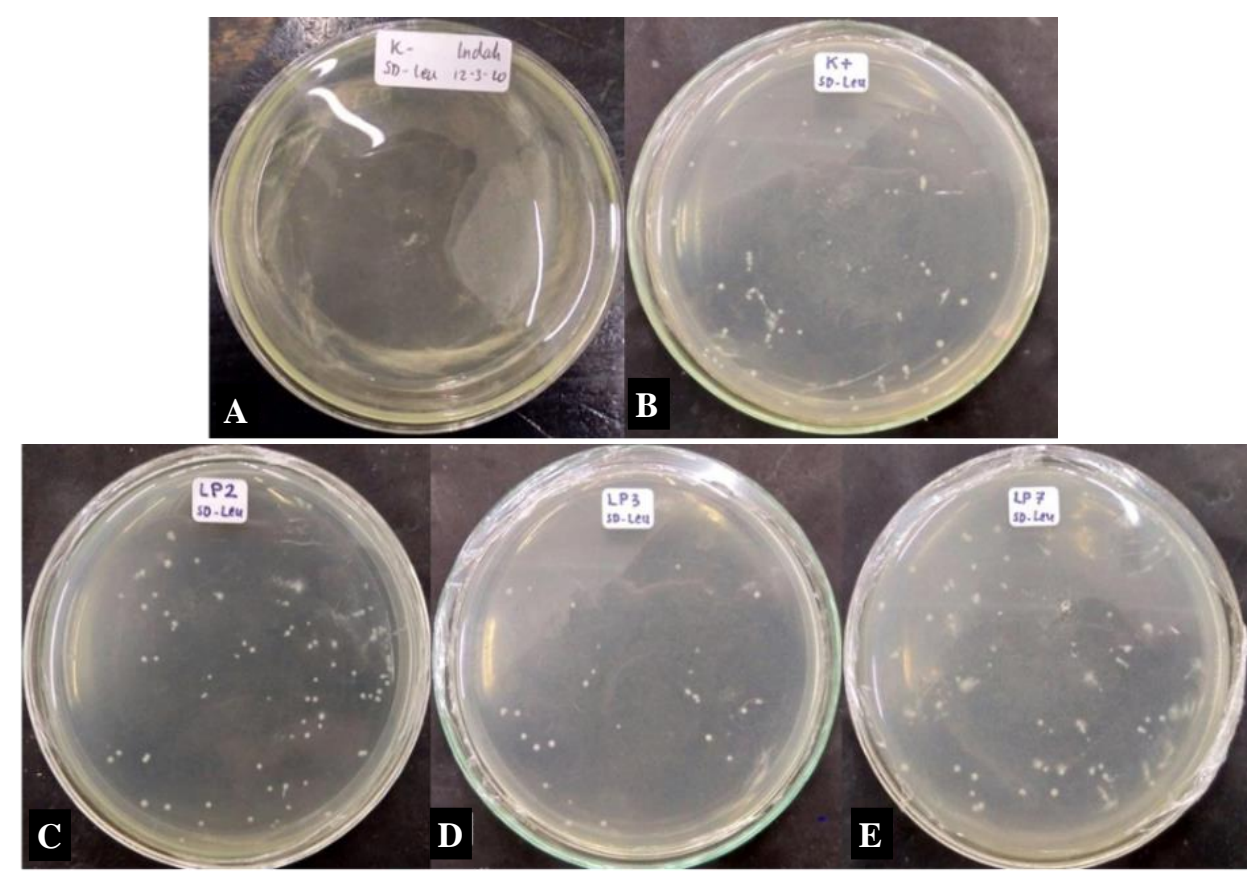

Figure 5. The results of transformation to Saccharomyces cerevisiae INVSc1 on Synthetic Drop-Out without Leucine agar medium. A. Competent cells of Saccharomyces cerevisiae INVSc1 as negative control, B. Plasmid pWYH257 as positive control, C. Transformants of LP2, D. Transformants of LP3, E. Transformants of LP7

The study results showed that the cellulase gene ( $c b h A$ gene) can be inserted into vector with strong promoter (pYY1 and pWYH257), and the recombinant containing the cbhA gene can be transformed into competent cells of Escherichia coli DH10B and the recombinant plasmid with
pYY1 vector was successfully transformed into Saccharomyces cerevisiae INVSc1. Construct with strong promotor will have large effects on the production of the target protein (Tegel et al. 2011), and will produce more abundant cellulase protein. More cellulase protein 
expressed in S. cerevisiae, this strain will be more powerful to hydrolase cellulose. These results play an important role in the development of research on the formation of cellulosic ethanol-producing strain, so the strains will be able to produce enzymes by themselves in cellulose hydrolysis process in the bioethanol industry. In conclusion, cbhA gene from Aspergillus niger measuring 1,514 bp was successfully amplified and inserted in the yeast expression vector pYY1 with $A D H 1$ promoter and pWYH257 with TEF1 promoter as candidate for yeast cellulosic ethanol-producing strain.

\section{ACKNOWLEDGEMENTS}

This research was financially supported by the 2020 UGM Faculty of Biology Lecturer and Student Collaboration Research Grant and the 2019 UGM (Universitas Gadjah Mada, Yogyakarta) Young Lecturer Research Grant. The author would like to thank Prof. Chien Chia Wang from National Central University, Taiwan, Sumarno from Laboratory of Microbiology, Faculty of Biology, Universitas Gadjah Mada, Aries Bagus Sasongko from Laboratory of Biotechnology and Arsiyah from Laboratory of Microbiology, Biotechnology Study Center (PAU), Universitas Gadjah Mada.

\section{REFERENCES}

Akorede FM, Hizam H, Pouresmaeil E. 2010. Distributed energy resources and benefits to the environment. Renew Sustain Energ Rev 14: 724. DOI: $10.1016 /$ j.rser.2009.10.025.

Busic A, Mardetko N, Kundas S, Morzak G, Belskaya H, Santek B. 2018. Bioethanol production from renewable raw materials and its separation and purification. Food Technol Biotechnol 56 (3): 296. DOI: $10.17113 / \mathrm{ftb} .56 .03 .18 .5546$.

Fabre AL, Colotte M, Luis A, Tuffet S, Bonnet J. 2014. An efficient method for long-term room temperature storage of RNA. Eur J Hum Genet 22 (3): 379-385. DOI: 10.1038/ejhg.2013.145.

Gohel HR, Contractor CN, Ghosh SK, Bragaza VJ. 2014. A Comparative study of various staining techniques for determination of extracellular cellulase activity on carboxy methylcellulose (CMC) agar plates. Int J Curr Microbiol Appl Sci 3: 261-266.

Hasan MH, Mahlia TMI, Nur H. 2012. A review on energy scenario and sustainable energy in Indonesia. Renew Sustain Energy Rev16: 23162317. DOI: 10.1016/j.rser.2011.12.007.

Jamal MAHM, Sharma SP, Chung HJ, Kim HJ, Hong ST, Lee S. 2017. Ultra-high efficient colony PCR for high throughput screening of bacterial genes. Indian J Microbiol 57 (3): 365-369. DOI: $10.1007 / \mathrm{s} 12088-017-0665-1$
Jo BS, Choi SS. 2015. Introns: The functional benefits of introns in genomes. Genomics Inform 13 (4): 112-118. DOI: 10.5808/GI.2015.13.4.112.

Li S, Bashline L, Lei L, Gu Y. 2014. Cellulose Synthesis and Its Regulation. Arabidopsis Book 12: e0169. DOI: 10.1199/tab.0169.

Kholiq I. 2015. Pemanfaatan energi alternatif sebagai energi terbarukan untuk mendukung substitusi BBM. Jurnal IPTEK 19 (2): 83. [Indonesian]

Motkova P, Vytrasova J. 2011. Comparison of methods for isolating fungal DNA. Czech J Food Sci 29 (1): 77-78. DOI: 10.17221/266/2011-CJFS

Muammar A, Fajrin SAR, Retnaningrum E. 2020. Cellobiohydrolase A (CBHA) gene cloning from Aspergillus niger to the yeast expression vector as a stage to create cellulosic ethanol strain. In: Saragih HT, Ilmi M, Nopitasari S (eds); Proceeding of THE 6th International Conference on Biological Science ICBS 2019: Biodiversity as a Cornerstone for Embracing Future Humanity. Universitas Gadjah Mada, Yogyakarta, 10-11 October 2019. [Indonesian]

Muammar A, Manullang M, Arjuna M, Retnaningrum E. 2021. Isolation of cellulolytic microbes from bio-slurry. Eksakta: Berkala Ilmiah Bidang MIPA 22 (1): 27-34.

Raj SB, Ramaswamy S, Plapp BV. 2014. Yeast alcohol dehydrogenase structure and catalysis. Biochemistry 56: 5791. DOI: 10.1021/bi5006442.

Song JM, Picologlou S, Grant CM, Firoozan M, Tuite MF, Liebman S. 1989. Elongation factor EF-l $\alpha$ gene dosage alters translational fidelity in Saccharomyces cerevisiae. Mol Cell Biol 9 (10): 4571-4575. DOI: 10.1128/MCB.9.10.4571.

Taheri A, Robinson SJ, Parkin I, Gruber MY. 2012. Revised selection criteria for candidate restriction enzymes in genome walking. PLoS One 7 (4): e35117. DOI: 10.1371/journal.pone.0035117

Tegel H, Ottosson J, Hober S. 2011. Enhancing the protein production levels in Escherichia coli with a strong promoter. FEBS J 278 (5): 729-739. DOI: 10.1111/j.1742-4658.2010.07991.x.

van Munster JM, Daly P, Delmas S, Pullan ST, Blythe MJ, Malla S, Kokolski M, Noltorp ECM, Wennberg K, Fethersen R, Beniston R, Yu X, Dupree P, Archer DB. 2014. The role of carbon starvation in the induction of enzymes that degrade plant-derived carbohydrates in Aspergillus niger. Fungal Genet Biol 72: 35-45. DOI: 10.1016/j.fgb.2014.04.006.

Viikari L, Vehmaanpera J, Koivula A. 2012. Lignocellulosic ethanol: From science to industry. Biomass Bioenerg 46: 13-15. DOI: 10.1016/j.biombioe.2012.05.008.

Wakasugi K, Quinn CL, Tao N, Schimmel P. 1988. Genetic code in evolution: switching species-specific aminoacylation with a peptide transplant. EMBO J 17 (1): 303. DOI: 10.1093/emboj/17.1.297.

Wang J, Huang C, Guo K, Ma L, Meng X, Wang N, Huo YX. 2020. Converting Escherichia coli MG1655 into a chemical overproducer through inactivating defense system against exogenous DNA. Synth Syst Biotechnol 5 (4): 333-342. DOI: 10.1016/j.synbio.2020.10.005.

Yang W, Meng F, Peng j, Han P, Fang F, Ma L, Cao B. 2014. Isolation and identification of a cellulolytic bacterium from the Tibetan pig's intestine and investigation of its cellulase production. Electronic $\mathrm{J}$ Biotechnol 17: 6262-267. DOI: 10.1016/j.ejbt.2014.08.002.

Xiong L, Zeng Y, Tang R, Alper HS, Bai F, Zhao X. 2018. Conditionspecific promoter activities in Saccharomyces cerevisiae. Microb Cell Fact 17 (58): 2. DOI: 10.1186/s12934-018-0899-6.

Yamada R, Taniguchi N, Tanaka T, Ogino C, Fukuda H, Kondo A. 2011. Direct ethanol production from cellulosic materials using a diploid strain of Saccharomyces cerevisiae with optimized cellulase expression. Biotechnol Biofuels 4: 8. DOI: 10.1186/1754-6834-4-8. 